Article

\title{
An Examination of the Electron Densities in a Series of Tripodal Cobalt Complexes Bridged by Magnesium, Calcium, Strontium, and Barium ${ }^{\dagger}$
}

\author{
John Bacsa ${ }^{1, *}$, Lillian G. Ramírez-Palma ${ }^{2}$, Fernando Cortés-Guzmán ${ }^{2}$, Christian M. Wallen ${ }^{1}$ \\ and Christopher C. Scarborough ${ }^{1}$ \\ 1 Department of Chemistry, Emory University, 1515 Dickey Dr., Atlanta, GA 30322, USA; \\ christian.wallen@alumni.emory.edu (C.M.W.); christophercscarborough@gmail.com (C.C.S.) \\ 2 Instituto de Química, Universidad Nacional Autónoma de México, Circuito Exterior, Ciudad Universitaria, \\ México 04510, Mexico; lila.gis.rp@gmail.com (L.G.R.-P.); fercor@unam.mx (F.C.-G.) \\ * Correspondence: jbacsa@emory.edu; Tel.: +1-404-727-6140 \\ + Dedicated to Professor Kim Dunbar.
}

Received: 10 May 2018; Accepted: 19 May 2018; Published: 25 May 2018

\begin{abstract}
X-ray crystallographic and theoretical charge-density data for a series of compounds$\left[\left(\mathrm{Co}\left(\mathrm{Ts}_{3}\right.\right.\right.$ tren $\left.)\right) \mathrm{M}\left(\mathrm{Co}\left(\mathrm{Ts}_{3}\right.\right.$ tren $\left.\left.)\right)\right],(\mathrm{M}=\mathrm{Mg}, \mathrm{Ca}, \mathrm{Sr}$ and $\mathrm{Ba})$-were examined. The crystal structures were isostructural, and the alkaline-earth-metal ions had the same six-coordinate environment oxygen donor atoms which was octahedral despite the large variation in their ionic radii. The isomorphism of these molecules was surprising, and a theoretical examination of their electronic structures, with various metal ions along the series, provided detailed insight into their stabilities. The theoretical and experimental data were consistent and agreed well. The local properties of the $\mathrm{Co}(\mathrm{II})$ ion and its donor atoms were relatively independent of the alkaline earth metals.
\end{abstract}

Keywords: quantum theory of atoms in molecules (QTAIM); alkaline earth metals; theoretical electron densities

\section{Introduction}

Spectroscopic and electrochemical data, and preliminary X-ray crystallographic data for a series of compounds- $\left[\left(\mathrm{Co}\left(\mathrm{Ts}_{3}\right.\right.\right.$ tren $\left.)\right) \mathrm{M}\left(\mathrm{Co}\left(\mathrm{Ts}_{3}\right.\right.$ tren $\left.\left.)\right)\right],(\mathrm{M}=\mathrm{Mg}, \mathrm{Ca}, \mathrm{Sr}$ and $\mathrm{Ba})$-were reported [1]]. The results showed that the cobalt(II) anions were in an unusual four-coordinate environment, which was trigonal pyramidal. The fourth nitrogen atom above the triangle of three nitrogen atoms formed the apex of the trigonal pyramid, but the fifth site in the potential trigonal bipyramid was vacant; instead, a redox-inert alkaline earth metal was nearby. The alkaline earth metal bridged two trigonal-pyramidal cobalt(II) anions. The bridging symmetry was enforced by a crystallographic inversion center. Six oxygen atoms, three from three Ts groups of one $\left[\left(\mathrm{Co}\left(\mathrm{Ts}_{3} \text { tren }\right)\right)\right]^{1-}$ complex and another three from the second $\left[\left(\mathrm{Co}\left(\mathrm{Ts}_{3} \text { tren }\right)\right)\right]^{1-}$ complex, were bound to the alkaline earth metal. The triangles of the three oxygen atoms above and below the alkaline earth metal were twisted through an angle of $45^{\circ}$ relative to one another about the vertical axis (the Co-M-Co axis), forming a trigonal antiprism, and an overall octahedral arrangement of oxygen atoms. The crystal structures were isostructural, and the $\mathrm{M}^{2+}$ ions had the same octahedral arrangement of six sulfonamide oxygen atoms. The $\mathrm{M}^{2+}$ atoms were placed at the Wyckoff position -3, where the 3-fold axis and the inversion center intersect, for all the alkali-earth metals. The $\mathrm{O}$ atoms occupy the same crystallographic sites in the four structures. The isomorphism of these molecules was surprising because the magnesium and barium atoms are so different. Barium atoms favor much higher coordination numbers with weaker interactions. Because a six-coordinate $\mathrm{Mg}^{2+}$ ion is much more stable than a six-coordinate $\mathrm{Ba}^{2+}$ ion, it is reasonable to assume 
there was distortion and stress in the Ba-crystal. Thus, appreciable differences in the energies were expected across this series of compounds. Crystals of the Mg-compound were of the best quality, but most crystals of the Sr- and Ba-compounds were twinned, and their structures were disordered. The disordered crystals were made up of intimate components that were rotated about each other along the $c$-axis. We hypothesize that stress in compounds with larger ions may distort crystal lattices, causing crystallographic defects. Interestingly, although the neighboring domains possessed different orientations, splitting of the domains within the crystal coincided exactly with the $c$-axis, giving a hexagonal-packing motif. The disorder was borne out by twinning by inversion. Differences in the stabilities of the isomorphic compounds were also borne out by reactivity studies which showed the Ba-compound to be the least stable, and the most vulnerable to hydrolysis [1-3]. The poor solubility of the Mg-complex precluded its inclusion in the hydrolysis experiments, but the observed trend was $\mathrm{Ba}<\mathrm{Sr}<\mathrm{Ca}$, so it is reasonable to expect that the Mg-complex is also the least vulnerable to hydrolysis. We were interested to see whether the electronic nature of the cobalt ions, and whether the donor characteristics of the sulfonamide oxygen donors changed when the small, acidic $\mathrm{Mg}^{2+}$ ion was replaced by bigger ions. This was especially of interest because not only does the identity of the alkaline earth metal play a prominent role in catalysis [2-9], but spectroscopic profiling of interactions between these redox-inert metals and cobalt-supporting ligands through electron-rich sulfonamide oxygen donors is challenging. Elucidating the origin of the redox-inert effect of metal ions is critical to the potential development of these compounds as catalysts for industrially important transformations. Spectroscopic and electrochemical techniques were employed to examine the cobalt chromophore, but these studies did not reveal any differences in the electronic structure of the cobalt ion, as a function of the identity of the alkaline earth metal. Therefore, charge-density studies of these compounds were performed using diffraction data from single crystals, and quantum-mechanical calculations. Electron densities were analyzed using the quantum theory of atoms in molecules (QTAIM) [10]. Specifically, local properties at the bond critical points, and atomic charges for the cobalt ions, sulfonamide oxygen donors, and alkaline earth metals were compared and trends examined. Delocalization indices were calculated to examine the basic pattern of interactions between the alkaline earth metals and the oxygen donor atoms, and of interactions between Co atoms separated by the alkaline earth metal. The amount of electron sharing between atom basins (i.e., the degree of delocalization) was derived from the exchange density. The QTAIM atomic charges and delocalization indices between two atomic basins gave reasonable indications of the formal charges and bond orders between atoms in the complexes, except for the ionic M-O bonds, as evidenced by their similarity to the values derived from the simplified Lewis model of the chemical bonding. These results showed the effects of the $\mathrm{M}(\mathrm{Mg}, \mathrm{Ca}, \mathrm{Sr}$, and $\mathrm{Ba})$ substitutions on the electron density distribution, and hence, their potential catalytic activity. We found that the alkaline earth metals had a very small observable effect on the transition metals, despite them having a dramatic effect on the reactivity and stability of the compounds. The energy differences of the isolated molecules were found to be small, with similar electron distributions about the cobalt atoms (except for the Ba-compound which had a stronger axial Co-N bond).

\section{Materials and Methods}

The theoretical electron densities of $\left[\mathrm{C}_{36} \mathrm{H}_{78} \mathrm{MCo}_{2} \mathrm{~N}_{8} \mathrm{O}_{12} \mathrm{~S}_{6}\right]$, where $\mathrm{M}$ was $\mathrm{Mg}$, $\mathrm{Ca}$, $\mathrm{Sr}$, or $\mathrm{Ba}$, were obtained using the M06-2X functional with a double-zeta plus polarization Douglas-Kroll-Hess (DZP-DKH) basis set. The M06-2X functional performed reasonably well when benchmarked against both coupled-cluster-single-double-perturbative-triple (CCSD(T)) and experimental results for structures, dissociation energies, and vibrational frequencies of alkaline-earth compounds [11]. The DZP-DKH is a contracted Gaussian basis set of double-zeta-valence qualities plus polarization functions, with contraction coefficients optimized using the relativistic DKH Hamiltonian for elements $\mathrm{H}$ to $\mathrm{Kr}$ [12], and Cs to Rn [13]. This theoretical level allowed us to analyze and compare the complexes featuring the four alkaline earth metals. The Kohn-Sham molecular orbitals of each 
complex were obtained with Gaussian 09 software [14], and the local and integrated properties of electron density were calculated with the AIMAll suite of programs [15]. Quality X-ray charge-density data were accessible for the Mg- and Ca-complexes, but not for the other compounds due to issues related to crystal quality and twinning. Multipolar refinements [16] were applied with a multipole expansion of the valence shell, up to hexadecapoles, for $\mathrm{Co}, \mathrm{S}, \mathrm{Mg}, \mathrm{Ca}, \mathrm{O}$, and $\mathrm{N}$ atoms. Hartree-Fock functions were used for the core- and spherical-valence densities. Conventional refinements, where the charge-density parameters- $P_{v}, P_{l m}$, and $\kappa$-were optimized on the experimentally measured X-ray structure factors, were carried out [17]. The charge-density parameters $-P_{v}, P_{l m}, \kappa$-were also obtained for $\mathrm{Co}, \mathrm{S}, \mathrm{O}$, and $\mathrm{N}$ atoms from non-relativistic wave-function calculations through a published procedure [18]. In this procedure, density-functional calculations are performed on the experimental charge-density-optimized atomic coordinates. The program TONTO [19] was used to calculate structure factors from the theoretical electron density. The differences in orbital populations derived from the experimental data and from the theoretical densities were within $1 \%$.

\section{Results}

\subsection{The Crystal Structures of $\left[\left(\mathrm{Co}\left(\mathrm{Ts}_{3}\right.\right.\right.$ tren $\left.)\right) M\left(\mathrm{Co}\left(\mathrm{Ts}_{3}\right.\right.$ tren $\left.\left.)\right)\right]$}

Although the dimeric cobalt(II) complexes bridged by alkaline earth metals were isostructural, the smaller metals were more ordered, with the $\mathrm{Mg}$ - and Ca-compounds being the most ordered and well-crystallized of the series. The molecular structure of the Mg-compound, shown in Figure 1, will be discussed in the most detail. The molecule was located on a 3-fold rotation axis through atoms $\mathrm{Mg}(1), \mathrm{Co}(1)$, and $\mathrm{N}(1)$. Each magnesium ion served as a bridge between two Co atoms, and formed a very interesting column along the $c$-axis. As these atoms were situated on the rotation axis, the entire $\mathrm{N}(1)-\mathrm{Co}(1)-\mathrm{Mg}-\mathrm{Co}(1)^{\prime}-\mathrm{N}(1)^{\prime}$ system was linear, within experimental error, by crystallographic symmetry. Both Co-Mg distances were equal to 3.408(1) $\AA$. Each Co atom was coordinated to four $\mathrm{N}$ atoms in a trigonal-pyramidal arrangement with $C_{3 v}$ symmetry. The implication was that the symmetry of orbitals on the two cobalt atoms (and the apical $\mathrm{N}$ atoms) were constrained by crystallographic symmetry, and also had local $C_{3 v}$ symmetry. However, we did not impose this 3-fold symmetry in the quantum-mechanical calculations. On the other hand, we did retain the overall inversion symmetry of the molecule during the calculations. In the multipolar model, the spherical-harmonics functions with $m=1,2$, 4 were forbidden, but $m=0,3$ were allowed for this symmetry. An interesting feature, from a bonding and charge-density perspective, was that the cobalt atom was missing an apical ligand (i.e., there was no ligand forming a bipyramid for dative bonds with cobalt). The electron-rich sulfonamide oxygen atoms were a long distance from the Co atom (2.966(3) $\AA$ in the Ca-compound, and 2.863(3) $\AA$ in the Mg-compound). Instead, there was a $\mathrm{M}^{2+}$ ion at the apical position. Interactions between $\mathrm{Co}$ and these sulfonamide oxygen atoms could not be ruled out, and one of the aims of this charge-density study was to determine the nature and the extent of these interactions. The $\mathrm{M}-\mathrm{O}$ bonds were expected to be completely ionic, and it was unlikely for there to be any spin-spin coupling between $\mathrm{Co}$ (II) cations because of their large separation and with an absence of an spin-coupling pathway between them. The spin state was investigated using optimizations of unrestricted wave functions, and distributions of the spin densities in the molecule were visualized. The spin state was found to be nearly exactly $S=3 / 2$ at each cobalt atom, corresponding to a high-spin $\mathrm{d}^{7}$ configuration. The unrestricted value of $S$ was 3.0023 for the entire complex, and nuclear magnetic resonance (NMR) spectroscopy confirmed the assignment of $S=3 / 2$ [1].

\subsection{Theoretical Charge-Density Analysis of $\left[\mathrm{C}_{36} \mathrm{H}_{78} \mathrm{MCo}_{2} \mathrm{~N}_{8} \mathrm{O}_{12} \mathrm{~S}_{6}\right]$}

Table 1 shows the molecular graphs $[10,20]$ of $\left[\mathrm{C}_{36} \mathrm{H}_{78} \mathrm{MCo}_{2} \mathrm{~N}_{8} \mathrm{O}_{12} \mathrm{~S}_{6}\right]$ for each alkaline earth metal, where it was possible to observe, beside the covalent structure, an octahedral coordination sphere with six gradient paths between the alkaline earth metals and the sulfonamide oxygen atoms. 
The small coordination sphere of $\mathrm{Mg}$ allowed the presence of a path between adjacent oxygen atoms, which were also involved in non-conventional hydrogen bonds [21].

Table 2 presents the local properties at the bond critical points of selected interactions included in the molecular graph. In general, the alkaline-earth-metal-oxygen interactions were classified as closed-shell interactions with low values of electron densities and of electronic energy densities, along with positive Laplacian operators of electron density [22]. For closed shell interactions the curvature of the electron density along the interaction line is positive because charge is depleted at the interatomic surface. These local properties agreed with the ionic characteristics of the alkaline-earth-metal-oxygen interactions, and the configuration of the coordination sphere around the metal followed Gillespie's rules [23]. There were some trends in the local properties. The charge depletion $\left(\nabla^{2} \rho_{\mathrm{bcp}}\right)$ decreased with atomic number $(\mathrm{Z})$ of the alkaline earth metals, reducing the ionic characteristics of the interaction $\left(\nabla^{2} \rho_{\mathrm{bcp}}=-0.0015 \mathrm{Z}+0.2462, \mathrm{R}^{2}=0.93\right)$. The same conclusion could be obtained from the energy density, where potential energy density increased with atomic number. Electron delocalization between alkaline earth metals and the oxygen atom increased with covalent contribution. The $\mathrm{O}-\mathrm{O}$ contacts observed in the $\mathrm{MgL}_{2}$ complex presented features of very weak, closed-shell interactions. On the other hand, the coordination sphere of the cobalt center was composed of four bond paths, with nitrogen atoms of the ligand in a trigonal-pyramidal configuration. On the basis of the properties of the bond critical points, $\mathrm{Co}-\mathrm{N}$ interactions presented features of directional metal-ligand interactions [24]. In general, equatorial ligands were strongly bonded to the cobalt atom (larger values of electron density, and its Laplacian operator), except in complexes with barium, which presented stronger axial metal-ligand interactions.

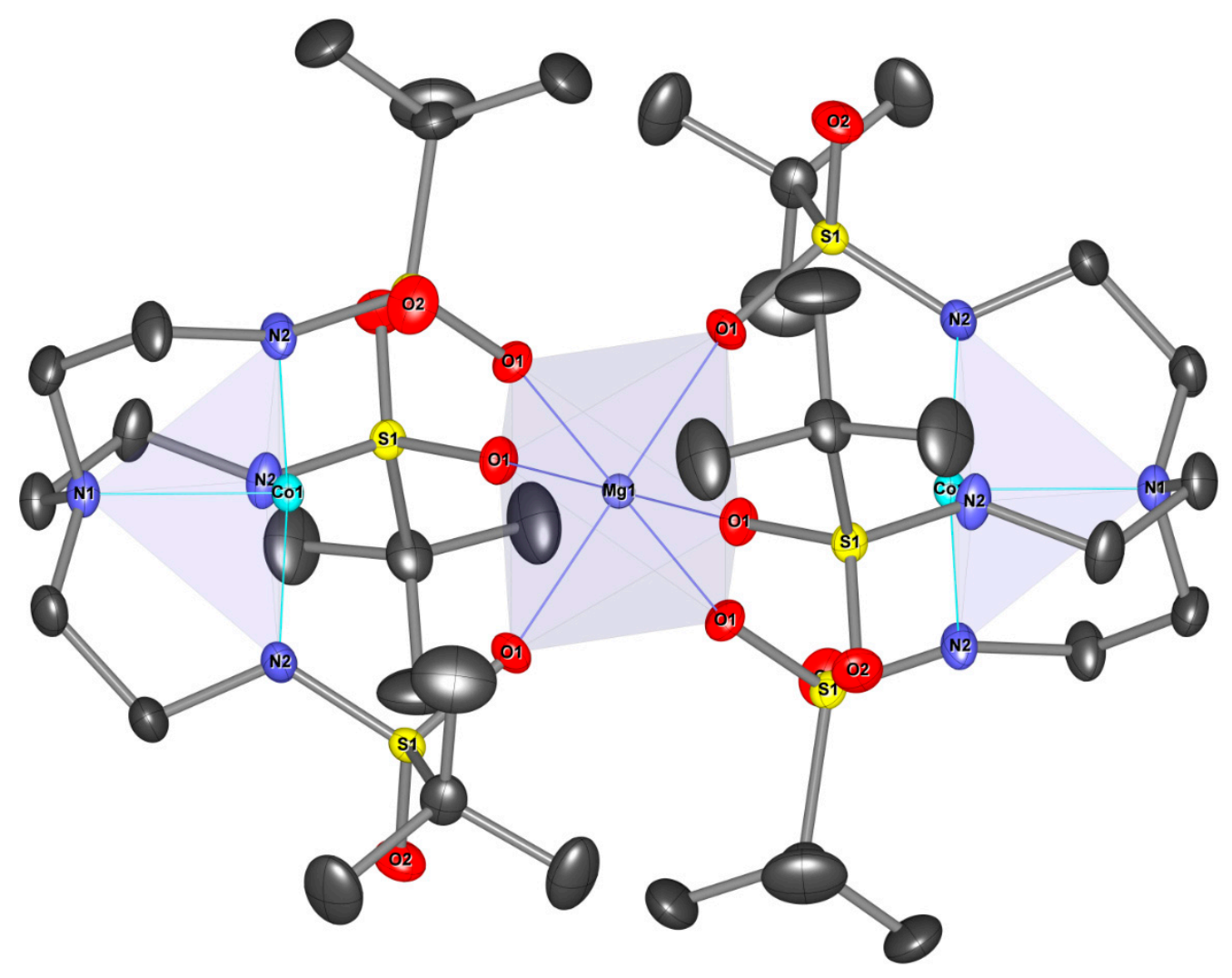

Figure 1. Thermal ellipsoid plot of the dimeric $\mathrm{Co}^{2+}$ complex, $\left[\left(\mathrm{Co}\left(\mathrm{Ts}_{3}\right.\right.\right.$ tren $\left.)\right) \mathrm{Mg}\left(\mathrm{Co}\left(\mathrm{Ts}_{3}\right.\right.$ tren $\left.\left.)\right)\right]$. Thermal ellipsoids are shown at the $79 \%$ probability level. 
Table 1. Molecular graph of the complexes.

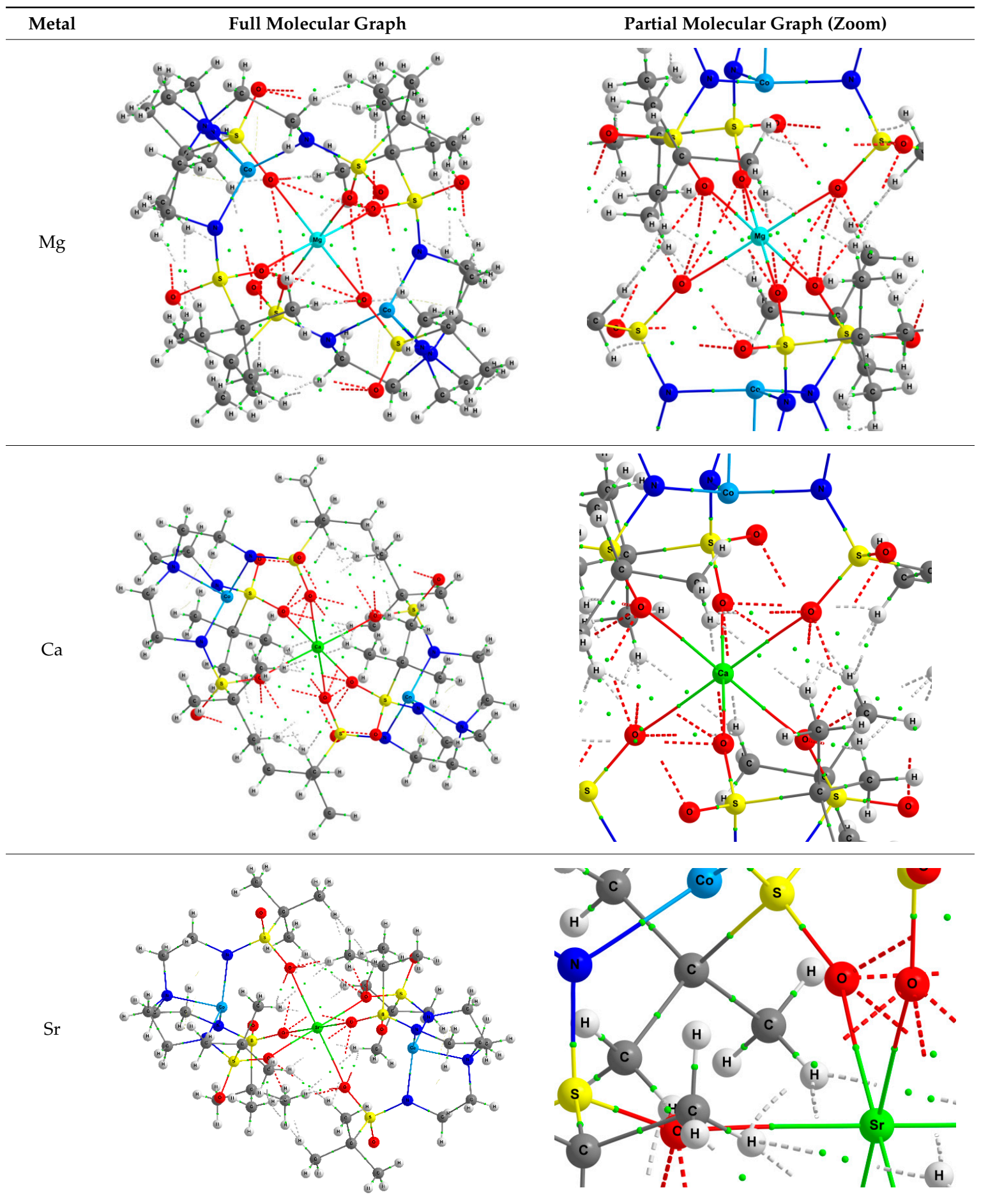


Table 1. Cont.

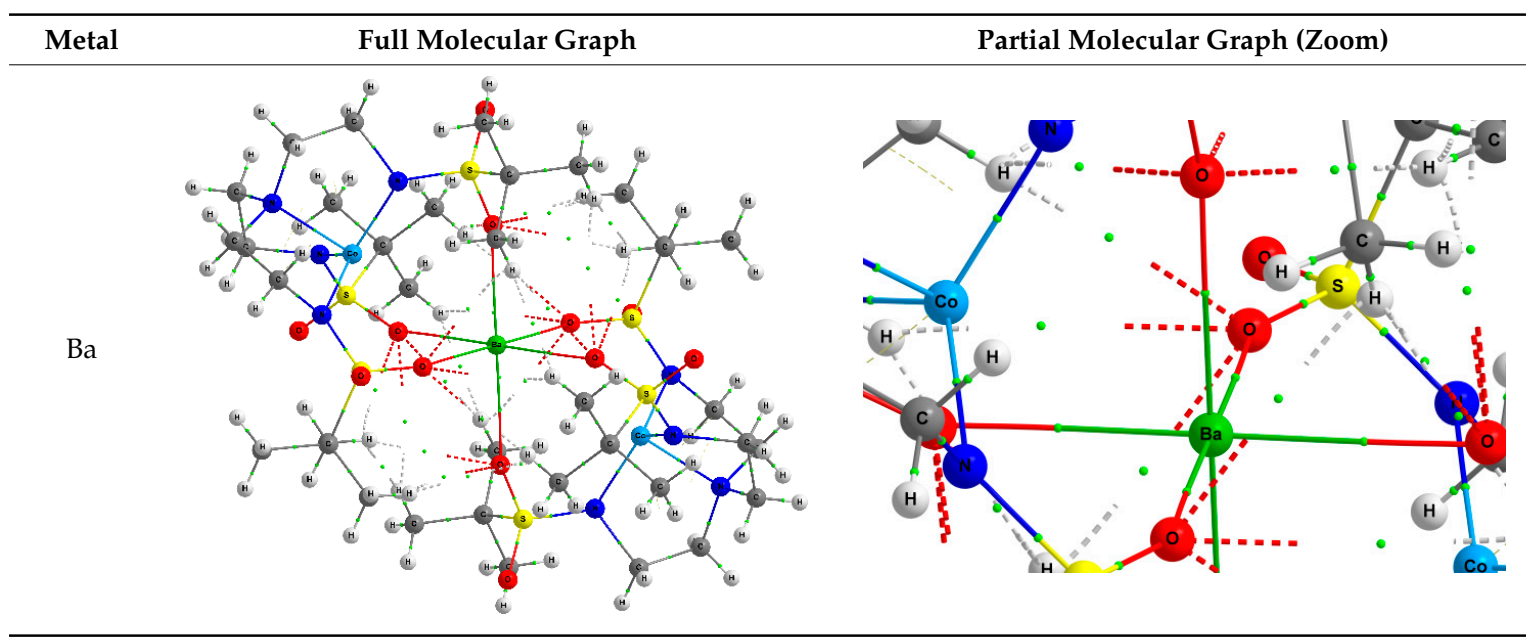

The contour map of the Laplacian operators of electron density of $\mathrm{MgL}_{2}$, displayed in Figure 2, showed the spherical distribution of charge concentration within the valence shell of the magnesium atom. It was also possible to observe the polarization of the valence shell of the cobalt metal center, with the charge depletions directed toward the charge concentrations of the nitrogen atoms. An interesting feature of the molecular graphs was the interatomic region between the magnesium and cobalt atoms, where an axial charge depletion of the cobalt valence shell faced a $(3,+3)$ critical point, which was a local minimum of the electron density. This feature was also observed in the other complexes (Table 3).

Table 2. Properties of the bond critical points, and delocalization of $\mathrm{M}-\mathrm{O}$ and $\mathrm{Co}-\mathrm{N}$ interactions.

\begin{tabular}{cccccc}
\hline \multirow{2}{*}{$\mathbf{M}^{2+}$} & $\rho_{\text {bcp }}$ & $\nabla^{2} \rho_{\text {bcp }}$ & $\varepsilon$ & $\mathbf{H}_{\text {bcp }}$ & DI (M I O) \\
\cline { 2 - 6 } & \multicolumn{5}{c}{$\mathbf{M}-\mathbf{O}$} \\
\hline $\mathrm{Mg}$ & 0.0282 & 0.2330 & 0.0016 & 0.0103 & 0.0793 \\
\hline $\mathrm{Ca}$ & 0.0326 & 0.2170 & 0.0158 & 0.0065 & 0.1293 \\
\hline $\mathrm{Sr}$ & 0.0330 & 0.1799 & 0.0259 & 0.0045 & 0.1676 \\
\hline $\mathrm{Ba}$ & 0.0305 & 0.1707 & 0.0279 & 0.0047 & 0.1630 \\
\hline \multirow{2}{*}{$\mathrm{Mg}$} & 0.0976 & 0.4739 & 0.2631 & -0.0233 & 0.5127 \\
\hline \multirow{2}{*}{$\mathrm{Ca}$} & 0.0697 & 0.3618 & 0.0005 & -0.0108 & 0.3350 \\
\hline \multirow{2}{*}{$\mathrm{Sr}$} & 0.0991 & 0.4851 & 0.2683 & -0.0237 & 0.5232 \\
& 0.0924 & 0.4469 & 0.2688 & -0.0203 & 0.5074 \\
\hline \multirow{2}{*}{$\mathrm{Ba}$} & 0.0889 & 0.4419 & 0.1913 & -0.0189 & 0.4634 \\
& 0.0972 & 0.4740 & 0.2859 & -0.0225 & 0.5228 \\
\hline
\end{tabular}

$\rho_{\mathrm{bcp}}=$ density at the bond critical point. $\nabla^{2} \rho_{\mathrm{bcp}}=$ Laplacian of $\rho_{\mathrm{bcp}} \cdot \varepsilon=$ bond ellipticity. $\mathrm{H}_{\mathrm{bcp}}=$ the local total energy density at the the bond critical point $\left(\mathrm{H}_{\mathrm{bcp}}=\mathrm{G}_{\mathrm{bcp}}+\mathrm{V}_{\mathrm{bcp}}\right)$. $\mathrm{DI}(\mathrm{MIO})=$ Electron delocalization index between atoms $\mathrm{M}$ and $\mathrm{O}$. 


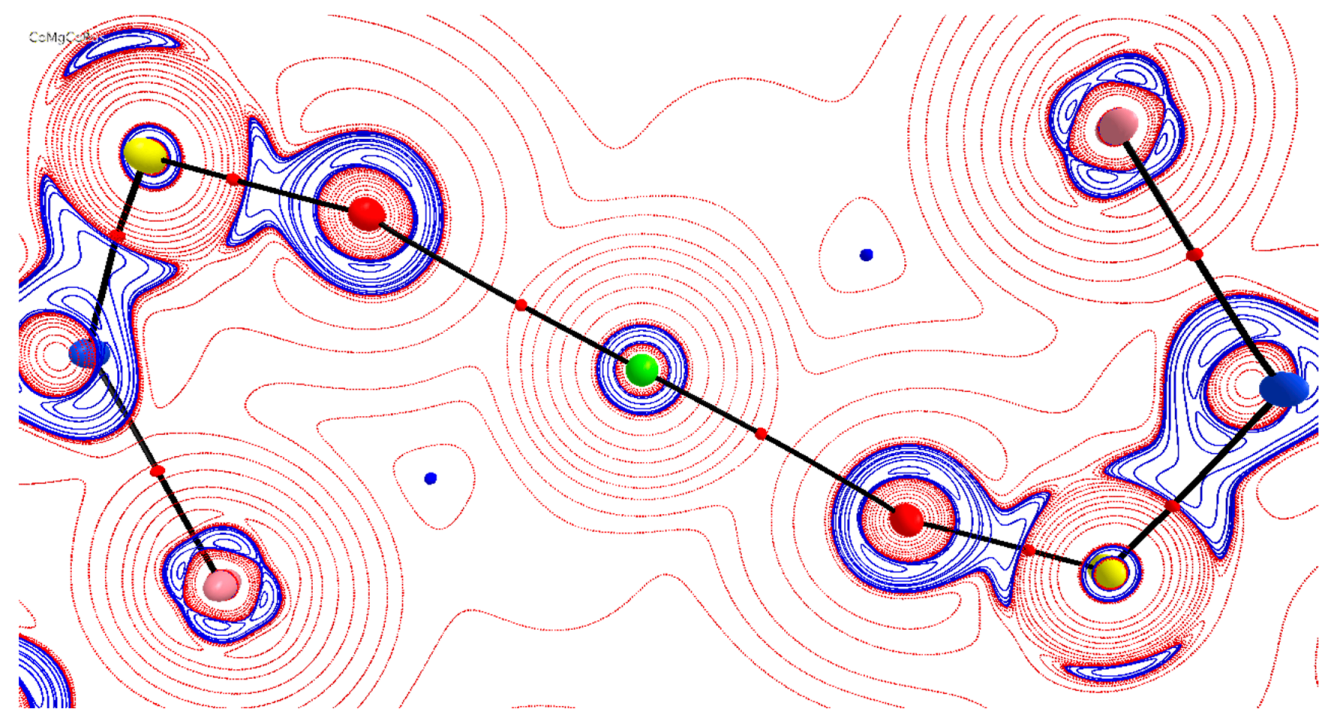

Figure 2. A contour map of the of the Laplacian operators of electron density in the plane of the $\mathrm{Mg}$, $\mathrm{Co}$, and oxygen donor atoms in the dimeric $\mathrm{Co}^{2+}$ complex, $\left[\left(\mathrm{Co}\left(\mathrm{Ts}_{3}\right.\right.\right.$ tren $\left.)\right) \mathrm{Mg}\left(\mathrm{Co}\left(\mathrm{Ts}_{3}\right.\right.$ tren $\left.\left.)\right)\right]$. The two small blue spheres are $(3,+3)$ critical points, which are local minima of the electron density between the magnesium and cobalt atoms.

Table 3. Molecular graph of the complexes.

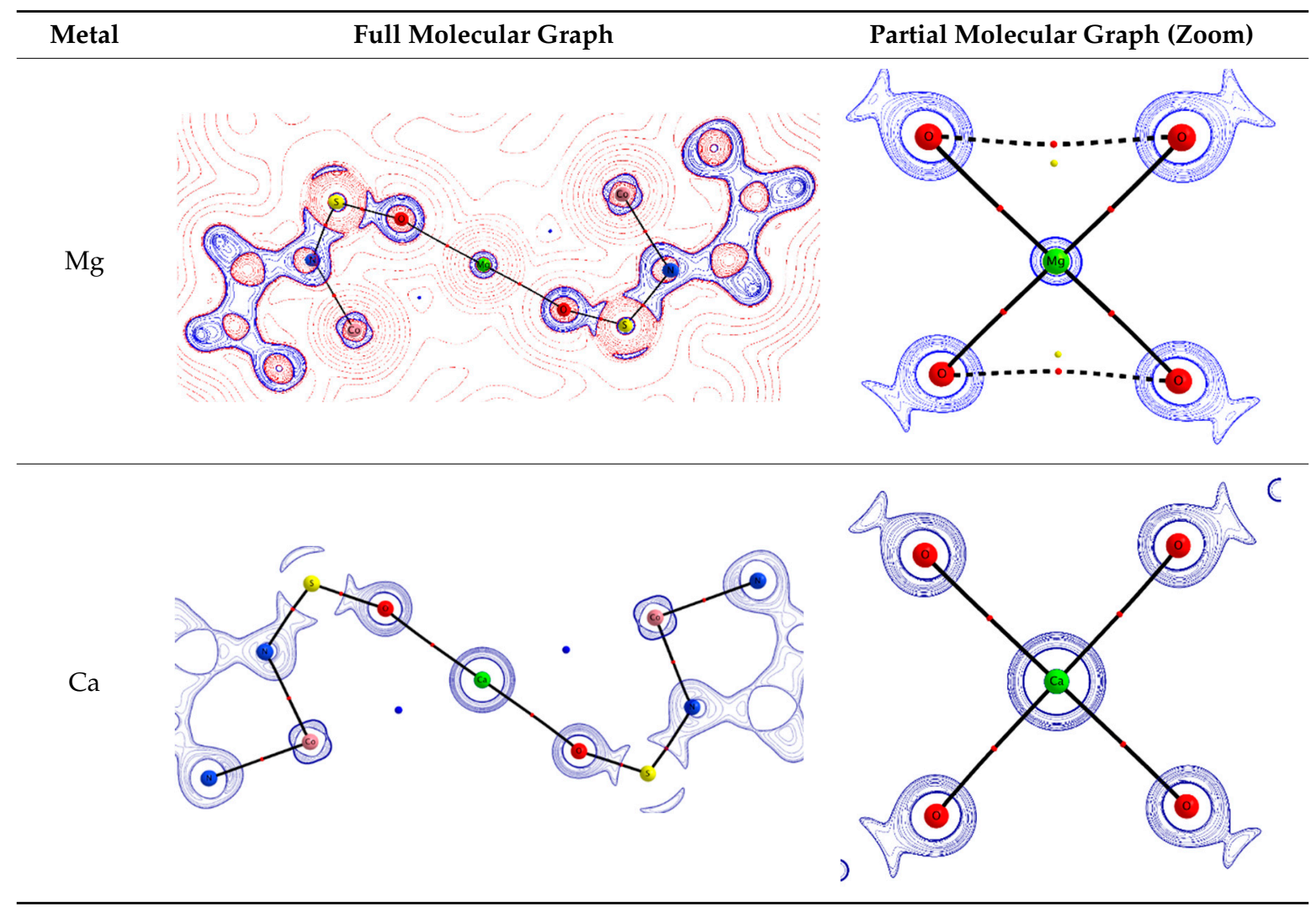


Table 3. Cont.

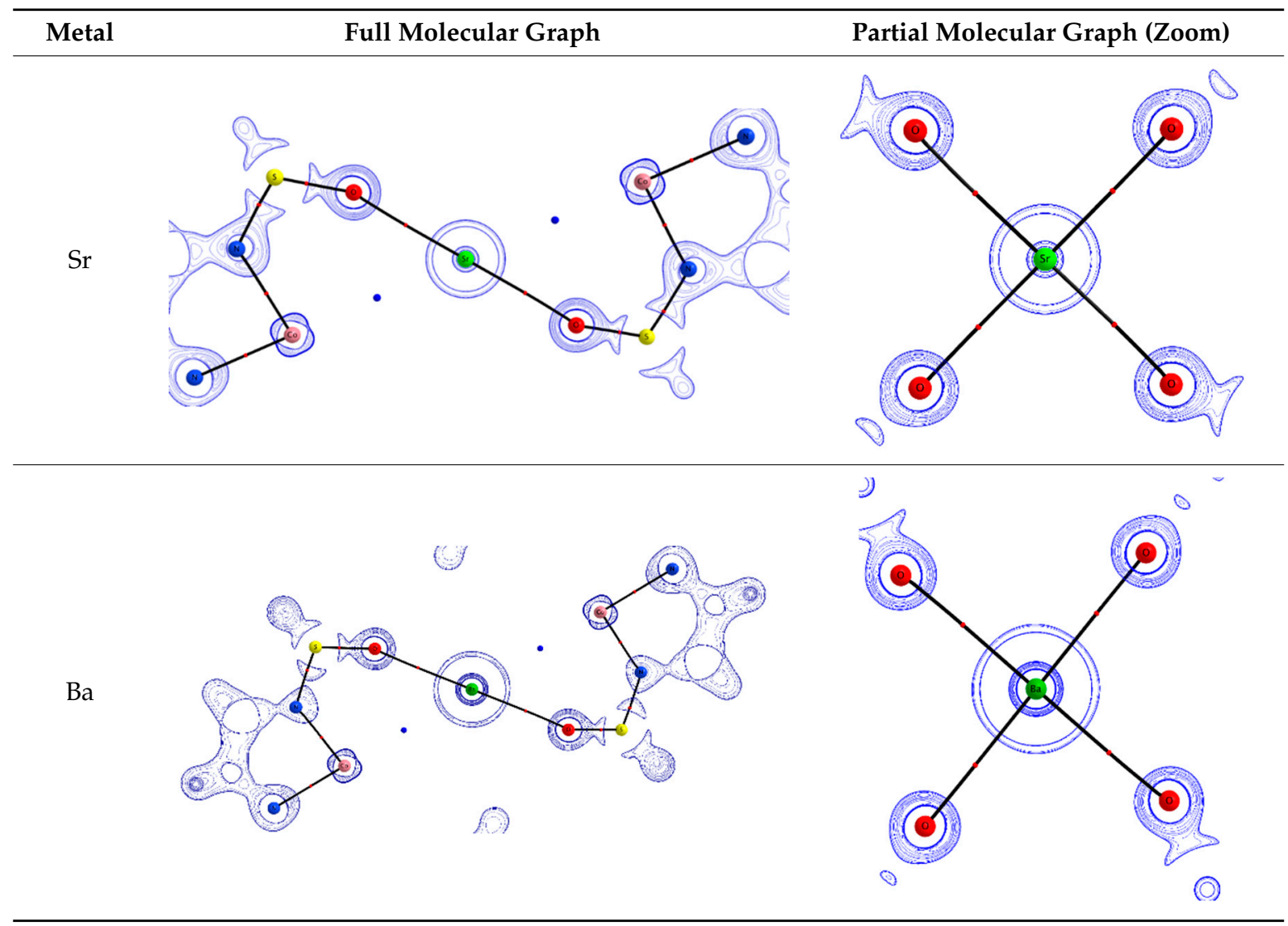

Table 4 presents selected atomic properties useful in showing the influence of the alkaline earth metals on the cobalt metal center. There was a nonlinear correlation between the atomic number of the alkaline earth metals and their electron delocalization indexes (DI) within the molecule as evidenced by the slope $\left(y=-0.0003 \mathrm{DI}^{2}+0.0256 \mathrm{DI}+0.0044, \mathrm{R}^{2}=0.99\right)$. The delocalization indexes of linked atoms through bond paths $\left(\mathrm{DI}_{\mathrm{B}}\right)$ presented the same correlation. Also, it was possible to observe correlations between non-bonded delocalization indexes $\left(\mathrm{DI}_{\mathrm{NB}}\right)$ and the atomic number $\left(\mathrm{DI}_{\mathrm{NB}}=1 \times 10^{-5} \mathrm{Z}^{2}-0.0015 \mathrm{Z}+0.2082, \mathrm{R}^{2}=0.99\right)$. There was a correlation between the $\mathrm{DI}_{\mathrm{B}}$ of the alkaline earth metals $\left(\mathrm{DI}_{\mathrm{B}}(\mathrm{M})\right)$ and the $\mathrm{DI}_{\mathrm{NB}}$ of the cobalt atom $\left(\mathrm{DI}_{\mathrm{NB}}(\mathrm{Co})\right)$, where an increase in the $\mathrm{DI}_{\mathrm{B}}(\mathrm{M})$ was associated with a decrease in the $\mathrm{DI}_{\mathrm{NB}}(\mathrm{Co})$.

Table 4. Integrated properties of the $\mathrm{M}^{2+}$ and Co atoms.

\begin{tabular}{ccccccccc}
\hline Atom & & $\mathbf{q}(\mathbf{A})$ & $\mathbf{N}(\mathbf{A})$ & $\mathbf{L I}(\mathbf{A})$ & $\mathbf{D I}$ & $\mathbf{D I}_{\mathbf{B}}$ & $\mathbf{D I}_{\mathbf{N B}}$ & $\mathbf{E}(\mathbf{A})$ \\
\hline \multirow{4}{*}{$\mathrm{M}^{2+}$} & $\mathrm{Mg}$ & 1.8168 & 10.1832 & 9.924 & 0.2591 & 0.2378 & 0.0213 & -199.2018 \\
& $\mathrm{Ca}$ & 1.8158 & 18.1842 & 17.7603 & 0.4239 & 0.4058 & 0.0181 & -676.1906 \\
& $\mathrm{Sr}$ & 1.7665 & 36.2335 & 35.6785 & 0.5550 & 0.5027 & 0.0523 & -3108.0289 \\
& $\mathrm{Ba}$ & 1.9283 & 54.0717 & 53.5193 & 0.5523 & 0.4892 & 0.0631 & -8363.3441 \\
\hline \multirow{6}{*}{$\mathrm{Co}$} & $\mathrm{Mg}$ & 1.3174 & 25.6826 & 24.5528 & 1.1297 & 0.9365 & 0.1933 & -1379.8770 \\
& $\mathrm{Ca}$ & 1.3133 & 25.6867 & 24.5496 & 1.1372 & 0.9535 & 0.1836 & -1380.2187 \\
& $\mathrm{Sr}$ & 1.3118 & 25.6882 & 24.5805 & 1.1077 & 0.9342 & 0.1735 & -1381.6302 \\
\cline { 2 - 8 } & $\mathrm{Ba}$ & 1.3098 & 25.6902 & 24.5639 & 1.1263 & 0.9565 & 0.1699 & -1242.0423 \\
\hline
\end{tabular}

$\mathrm{q}(\mathrm{A})=$ charge on atom $\mathrm{A} . \mathrm{N}(\mathrm{A})=$ average electron population of atom $\mathrm{A}$. $\mathrm{LI}(\mathrm{A})$ = average number of electrons localized on atom $\mathrm{A}$. DI = average number of electrons in atom $\mathrm{A}$ that are shared between atom $\mathrm{A}$ and other atoms in the molecule. $\mathrm{DI}_{\mathrm{B}}=$ bonding contribution to the delocalization index $\mathrm{DI}$. $\mathrm{DI}_{\mathrm{NB}}=$ non-bonding contribution to the delocalization index DI. E(A) = electronic energy of atom A. 


\subsection{Visualisation and Qualitative Analysis of the Deformation Density of the [(Co(Ts 3 tren $)) M\left(C o\left(T_{3}\right.\right.$ tren $\left.\left.)\right)\right]$ Complexes}

Visually, the qualitative characteristics of the deformation electron density (ED) appeared to be very similar for the $\mathrm{Mg}-, \mathrm{Ca}-, \mathrm{Sr}-$, and $\mathrm{Ba}-$-compounds by visual inspection of their difference density maps. A deformation electron density map in the plane of the $\mathrm{Ca}^{2+}$ atom and two of the oxygen donor atoms, and in the plane of the $\mathrm{Co}^{2+}$ atom and two of the nitrogen donor atoms is shown in Figure 3. Four charge concentrations corresponding to the $\mathrm{d}$ electrons about the cobalt atom were visible. These were asymmetric, and appeared to be more dominant on the side facing the $\mathrm{Mg}^{2+}$ ion. A representation of the three-dimensional deformation density, showing the characteristics of the chemical bonding for the Ca-compound, is shown in Figure 4. There were concentrations of charge corresponding to the $\mathrm{d}$ and lone-pair electrons. The deformation density about $\mathrm{M}^{2+}$ was very nearly spherical, showing the purely ionic characteristics of this atom. The contour map in a cross section through the $\mathrm{Ca}$ atom and the two $\mathrm{O}$ atoms showed the minimal perturbation of the ED by the oxygen donor atoms. However, there was a complex distribution of charge about the $\mathrm{Co}^{2+}$ atom. There was an annular region of charge depletion in the xy-plane, containing the three equatorial $\mathrm{N}$ atoms. According to simple crystal field theory, $\mathrm{d}$ electrons in this region were repulsed by the electrostatic field of the $\mathrm{N}$ atoms, and the energy levels of the d electrons were expected to be higher, and their populations were expected to be lower in this region of the crystal field. In contrast, there were two nearly equivalent annular regions, with local charge concentrations at angles subtended by the equatorial $x y$-plane and the axial $z$-axis (containing the axial $\mathrm{N}$ atom). In each of these two regions, there were three charge maxima. Two nearly equivalent regions of charge depletion were present in the axial direction, directed both toward the axial $\mathrm{N}$ atom and toward the $\mathrm{Ca}$ atom. The charge depletions appeared to be smaller than the equatorial depletions. The two axial charge depletions were almost the same, although one was directed toward an axial ligand. This distribution of charge was what was expected on the basis of a simplified classical crystal-field picture of bonding. In trigonal-monopyramidal $\left(C_{3 v}\right)$ geometry, we would expect the $\mathrm{dx}^{2}-\mathrm{y}^{2}$ and $\mathrm{dxy}$ orbitals to be the most destabilized, with the $\mathrm{dxz}$ and dyz orbitals being degenerate and the lowest in energy, and the $\mathrm{dz}^{2}$ orbital being in the middle. This arrangement does depend on the relative donor strength of the sulfonamide and amine donors.

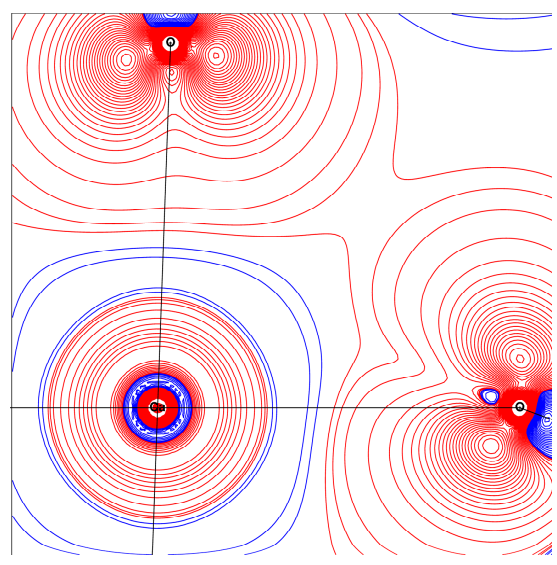

(a)

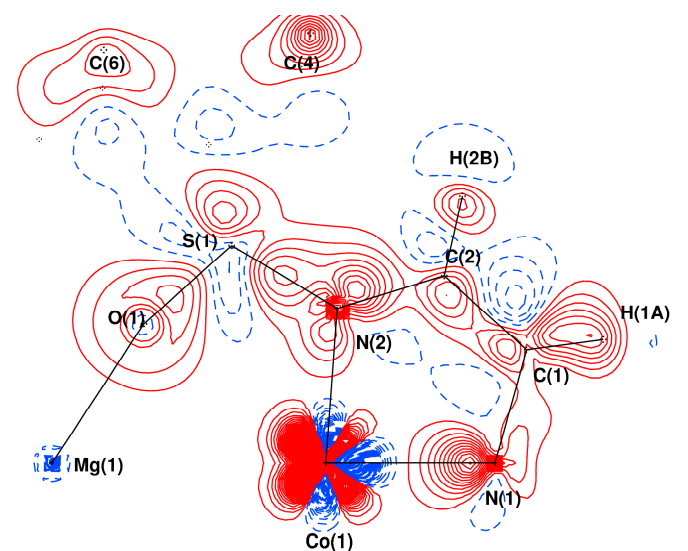

(b)

Figure 3. (a) A deformation electron density map in the plane of the $\mathrm{Ca}^{2+}$ atom and two of the oxygen donor atoms. The density is almost perfectly spherical about the calcium, and two lobes of density corresponding to the two pairs of lone-pair electrons about each oxygen atom are visible. Red lines represent positive contours, and blue lines represent negative contours. Contours are drawn at $0.1 \mathrm{e}^{-3}$ intervals. (b) A deformation electron density map in the plane of the $\mathrm{Co}^{2+}$ atom and two of the nitrogen donor atoms. Four charge concentrations corresponding to the $\mathrm{d}$ electrons about the cobalt atoms are visible, and two of these are larger towards the $\mathrm{Mg}^{2+}$ ion. Red lines represent positive contours, and blue lines represent negative contours. Contours are drawn at $0.1 \mathrm{e}^{-3}$ intervals. 


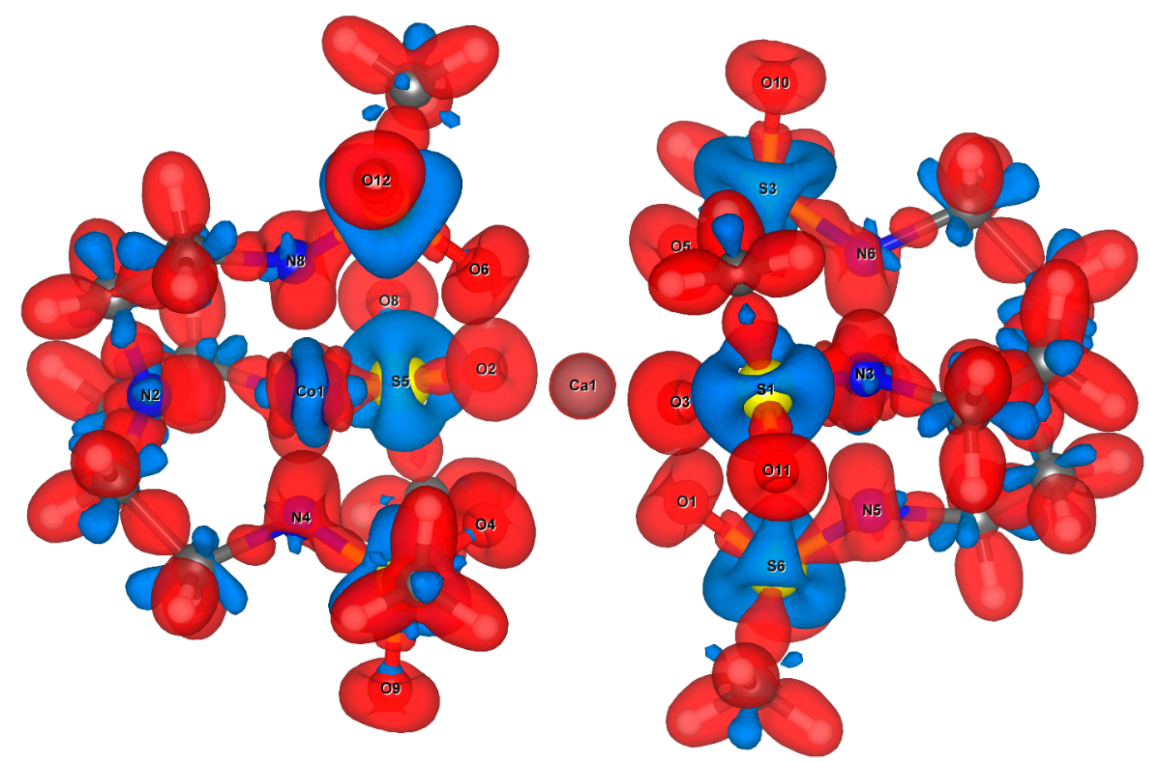

Figure 4. Positive and negative deformation-density isosurfaces $\left(0.02 \mathrm{e}^{-3}\right)$ of the dimeric $\mathrm{Co}^{2+}$ complex, $\left[\mathrm{C}_{36} \mathrm{H}_{78} \mathrm{CaCo}_{2} \mathrm{~N}_{8} \mathrm{O}_{12} \mathrm{~S}_{6}\right]$, from refinements with the predicted multipolar parameters. Charge concentrations are shown in red, and charge depletions are shown in blue.

\subsection{Comparison of Some Experimentally and Theoretically Derived Parameters}

Theoretical and experimental multipolar parameters for cobalt are compared in Table 5. D orbital populations were obtained from multipole populations, and are given in Table 6.

Table 5. Monopole populations (Pval), radial parameters ( $\mathrm{k}$ ), multipolar coefficients (dipole (D), quadrupoles $(\mathrm{Q})$, octupoles $(\mathrm{O})$, and hexadecapoles $(\mathrm{H})$ ), and atomic charges for cobalt from X-ray data (1), and from theoretical densities (2). Some coefficients are zero because the Co site corresponds to the Wyckoff position 3 and some multipolar functions do not have $C_{3}$ symmetry.

\begin{tabular}{ccc}
\hline & $\mathbf{1}$ & $\mathbf{2}$ \\
\hline Pval & $7.675(58)$ & 7.077 \\
Kappa & $0.996(6)$ & 1.003 \\
Net charge & -0.435 & -0.037 \\
$\mathrm{D}_{10}$ & $-0.218(22)$ & 0.004 \\
$\mathrm{Q}_{20}$ & $0.227(30)$ & 0.176 \\
$\mathrm{Q} 30$ & $-0.102(19)$ & 0.001 \\
$\mathrm{Q} 40$ & $-0.371(30)$ & -0.387 \\
$\mathrm{O} 32-$ & $0.05(2)$ & -0.001 \\
$\mathrm{H} 40$ & $0.27(3)$ & 0.235 \\
$\mathrm{H} 43+$ & $-0.087(27)$ & -0.045 \\
$\mathrm{H} 43-$ & $0.068(27)$ & -0.108 \\
\hline
\end{tabular}

Table 6. D orbital populations (\%) obtained from X-ray data (1), and from theoretical densities derived from theoretical multipolar parameters (2) following the method of Holladay et al.) [25].

\begin{tabular}{cccc}
\hline & $\mathbf{1}$ & $\mathbf{2} \mathbf{( M g})$ & $\mathbf{2}(\mathbf{C a})$ \\
\hline Orbital & & & \\
$\mathrm{z}^{2}$ & 16.2 & 15.0 & 16.6 \\
$\mathrm{xz}$ & 26.2 & 26.4 & 25.4 \\
$\mathrm{yz}$ & 26.2 & 26.4 & 24.2 \\
$\mathrm{x}^{2}-\mathrm{y}^{2}$ & 15.7 & 16.1 & 17.0 \\
$\mathrm{xy}$ & 15.7 & 16.2 & 16.8 \\
\hline
\end{tabular}




\section{Conclusions}

Accurate mapping of the electron density provided an experimental probe into the interactions around alkaline earth metals. Delocalization indexes between two atomic basins gave reasonable indications of formal charges and bond orders between atoms in the complexes. The differences in common atomic properties across the series were small, despite large differences in the stabilities of these compounds. The net atomic charges (Table 4) of the $\mathrm{M}^{2+}$ ions were ranged from +1.78 to +1.93 , and there was no clear trend in the variation of charges. Atomic charges for the cobalt(II) atoms were nearly identical across the series $(+1.31)$. It is worth noting that there was an uneven increase in bond delocalization indexes across the series $(\mathrm{Mg}(0.2378), \mathrm{Ca}(0.4058), \mathrm{Sr}(0.5027)$, and Ba (0.4892)), with a sudden increase between magnesium and calcium. These indexes gave a measure of the amount of electron-sharing between the magnesium and oxygen donor atoms. The atomic charges of the oxygen donor atoms with respect to the $\mathrm{M}^{2+}$ ions were very similar as evidenced by the nearly invariant value of $-1.46(1)$ across the series. We found that the alkaline earth metals had a very small observable effect on the transition metals, despite having a dramatic effect on the reactivity and stability of the compounds. The energy differences of the isolated molecules were found to be small, with similar electron distributions existing about the cobalt atoms (except for the Ba-compound which had a stronger axial $\mathrm{Co}-\mathrm{N}$ bond). The differences in reactivity need to be understood by examining the amount of energy released upon forming the reaction products (appreciably less energy may be released upon forming the hexa-aqua $\mathrm{Mg}^{2+}$ ion than upon forming the fully hydrated $\mathrm{Ba}^{2+}$ ion from the $\left[\left(\mathrm{Co}\left(\mathrm{Ts}_{3}\right.\right.\right.$ tren $\left.)\right) \mathrm{M}\left(\mathrm{Co}\left(\mathrm{Ts}_{3}\right.\right.$ tren $\left.\left.)\right)\right]$ compounds). However, there were subtle differences in the electron-density distributions in the $\mathrm{Co}-\mathrm{O}-\mathrm{Mg}-\mathrm{O}-\mathrm{Co}$ planes, in the bond critical points around the $\mathrm{Co}$ atom, and in the molecular graph of the Mg-compound. These slight variations indicated that a complete study of the reactivities of these compounds should include an analysis of the reaction products, and that QTAIM does not necessarily predict the relative stabilities of molecules a priori.

Author Contributions: C.S. and C.W. prepared the compounds, and performed the reactivity studies; J.B. carried out the diffraction experiments, and analyzed the data; L.G.R.-P. and F.C.-G. carried out the theoretical studies; J.B., F.C.-G., and C.W. wrote the paper.

Acknowledgments: We acknowledge the Emory X-ray Crystallography Facility for the X-ray structural analysis. We also acknowledge the use of the Rigaku SYNERGY-S diffractometer with a HYPIX detector, supported by the National Science Foundation, under grant CHE-1626172. We also acknowledge DGTIC-UNAM for the computer time (grant LANCAD-UNAM-DGTIC-194). John Bacsa acknowledges the use of resources of the Cherry L. Emerson Center for Scientific Computation.

Conflicts of Interest: The authors declare no conflict of interest.

\section{References}

1. Wallen, C.M.; Wielizcko, M.; Bacsa, J.; Scarborough, C.C. Heterotrimetallic sandwich complexes supported by sulfonamido ligands. Inorg. Chem. Front. 2016, 3, 142-149. [CrossRef]

2. Wallen, C.M.; Bacsa, J.; Scarborough, C.C. Coordination of Hydrogen Peroxide with Late-Transition-Metal Sulfonamido Complexes. Inorg. Chem. 2018, 57, 4841-4848. [CrossRef] [PubMed]

3. Bang, S.; Lee, Y.-M.; Hong, S.; Cho, K.-B.; Nishida, Y.; Seo, M.S.; Sarangi, R.; Fukuzumi, S.; Nam, W. Redox-inactive metal ions modulate the reactivity and oxygen release of mononuclear non-haem iron(III)-peroxo complexes. Nat. Chem. 2014, 6, 934-940. [CrossRef] [PubMed]

4. Hong, S.; Pfaff, F.F.; Kwon, E.; Wang, Y.; Seo, M.-S.; Bill, E.; Ray, K.; Nam, W. Spectroscopic Capture and Reactivity of a Low-Spin Cobalt(IV)-Oxo Complex Stabilized by Binding Redox-Inactive Metal Ions. Angew. Chem. Int. Ed. 2014, 53, 10403-10407. [CrossRef] [PubMed]

5. Lee, Y.-M.; Bang, S.; Kim, Y.M.; Cho, J.; Hong, S.; Nomura, T.; Ogura, T.; Troeppner, O.; IvanovićBurmazović, I.; Sarangi, R.; et al. A mononuclear nonheme iron(iii)-peroxo complex binding redox-inactive metal ions. Chem. Sci. 2013, 4, 3917-3923. [CrossRef] [PubMed]

6. Miller, C.G.; Gordon-Wylie, S.W.; Horwitz, C.P.; Strazisar, S.A.; Peraino, D.K.; Clark, G.R.; Weintraub, S.T.; Collins, T.J. A Method for Driving O-Atom Transfer: Secondary Ion Binding to a Tetraamide Macrocyclic Ligand. J. Am. Chem. Soc. 1998, 120, 11540-11541. [CrossRef] 
7. Monte-Pérez, I.; Kundu, S.; Ray, K. An Open-Shell Spin Singlet Copper-Nitrene Intermediate Binding Redox-innocent Metal Ions: Influence of the Lewis Acidity of the Metal Ions on Spectroscopic and Reactivity Properties. Z. Anorg. Allg. Chem. 2015, 641, 78-82. [CrossRef]

8. Park, Y.J.; Cook, S.A.; Sickerman, N.S.; Sano, Y.; Ziller, J.W.; Borovik, A.S. Heterobimetallic complexes with MIII-([small mu]-OH)-MII cores (MIII = Fe, Mn, Ga; MII = Ca, Sr, and Ba): Structural, kinetic, and redox properties. Chem. Sci. 2013, 4, 717-726. [CrossRef] [PubMed]

9. Yao, S.; Xiong, Y.; Vogt, M.; Grützmacher, H.; Herwig, C.; Limberg, C.; Driess, M. O-O Bond Activation in Heterobimetallic Peroxides: Synthesis of the Peroxide [LNi $\left.\left(\mu, \eta^{2}: \eta^{2}-\mathrm{O}_{2}\right) \mathrm{K}\right]$ and its Conversion into a Bis( $\mu$-Hydroxo) Nickel Zinc Complex. Angew. Chem. Int. Ed. 2009, 48, 8107-8110. [CrossRef] [PubMed]

10. Bader, R.F.W. Atoms in Molecules: A Quantum Theory; Clarendon Press: Wotton-under-Edge, UK, 1990.

11. Sun, Z.; Launder, A.M.; Schaefer, H.F. Prediction and Characterization of Alkaline-Earth $(\mathrm{M}=\mathrm{Be}, \mathrm{Mg}, \mathrm{Ca}, \mathrm{Sr}$, and $\mathrm{Ba}$ ) Metallacyclopentadienes and Relevant Derivatives. ChemistrySelect 2017, 2, 1442-1453. [CrossRef]

12. Jorge, F.E.; Neto, A.C.; Camiletti, G.G.; Machado, S.F. Contracted Gaussian basis sets for Douglas-Kroll-Hess calculations: Estimating scalar relativistic effects of some atomic and molecular properties. J. Chem. Phys. 2009, 130, 064108. [CrossRef] [PubMed]

13. Martins, L.S.C.; Jorge, F.E.; Franco, M.L.; Ferreira, I.B. All-electron Gaussian basis sets of double zeta quality for the actinides. J. Chem. Phys. 2016, 145, 244113. [CrossRef] [PubMed]

14. Frisch, M.J.; Trucks, G.W.; Schlegel, H.B.; Scuseria, G.E.; Robb, M.A.; Cheeseman, J.R.; Scalmani, G.; Barone, V.; Petersson, G.A.; Nakatsuji, H.; et al. Gaussian 16 Rev. B.01.; Wallingford, CT, USA, 2016.

15. Keith, T.A. AIMAll, 17.11.14 ed.; TK Gristmill Software: Overland Park, KS, USA, 2017.

16. Hansen, N.K.; Coppens, P. Testing aspherical atom refinements on small-molecule data sets. Acta Crystallogr. Sect. A 1978, 34, 909-921. [CrossRef]

17. Koritsanszky, T.H.; Su, Z.; Mallinson, P.R.; Richter, T.; Hansen, N.K. XD2006-A Computer Program Package for Multipole Refinement and Analysis of Electron Densities from Diffraction Data; 2006.

18. Bacsa, J.; Briones, J. Determination of the electron density in methyl ( \pm )-(1S,2S,3R)-2-methyl-1,3diphenylcyclopropanecarboxylate using refinements with X-ray scattering factors from wavefunction calculations of the whole molecule. Acta Crystallogr. Sect. C Cryst. Struct. Commun. 2013, 69, 910-914. [CrossRef] [PubMed]

19. Jayatilaka, D.; Grimwood, D.J. (Eds.) Tonto: A Fortran Based Object-Oriented System for Quantum Chemistry and Crystallography; Springer: Berlin/Heidelberg, Germany, 2003.

20. Bader, R.F.W. A quantum theory of molecular structure and its applications. Chem. Rev. 1991, 91, 893-928. [CrossRef]

21. Alkorta, I.; Rozas, I.; Elguero, J. Non-conventional hydrogen bonds. Chem. Soc. Rev. 1998, 27, $163-170$. [CrossRef]

22. Macchi, P.; Sironi, A. Chemical bonding in transition metal carbonyl clusters: Complementary analysis of theoretical and experimental electron densities. Coord. Chem. Rev. 2003, 238-239, 383-412. [CrossRef]

23. Gillespie, R.J.; Robinson, E.A. Models of molecular geometry. Chem. Soc. Rev. 2005, 34, 396-407. [CrossRef] [PubMed]

24. Cortés-Guzmán, F.; Bader, R.F.W. Complementarity of QTAIM and MO theory in the study of bonding in donor-acceptor complexes. Coord. Chem. Rev. 2005, 249, 633-662. [CrossRef]

25. Holladay, A.; Leung, P.; Coppens, P. Generalized relations between d-orbital occupancies of transition-metal atoms and electron-density multipole population parameters from X-ray diffraction data. Acta Crystallogr. Sect. A 1983, 39, 377-387. [CrossRef]

(C) 2018 by the authors. Licensee MDPI, Basel, Switzerland. This article is an open access article distributed under the terms and conditions of the Creative Commons Attribution (CC BY) license (http://creativecommons.org/licenses/by/4.0/). 